\title{
Low Grade Malignant (Borderline) Phyllodes Tumor of the Breast: Case Report and Review of Literature
}

\author{
Mazaher Ramezani ${ }^{1}$, Masoud Sadeghi ${ }^{2, *}$ \\ ${ }^{1}$ Molecular Pathology Research Center, Emam Reza Hospital, Kermanshah University of Medical Sciences, Kermanshah, Iran \\ ${ }^{2}$ Medical Biology Research Center, Kermanshah University of Medical Sciences, Kermanshah, Iran \\ *Corresponding author: sadeghi_mbrc@yahoo.com
}

\begin{abstract}
Phyllodes tumor (PT) of the breast is a rare disease usually presents as a large lump. The aim of this study was to report low grade malignant (borderline) PT of the breast in Kermanshah, Iran. A 55-year-old lady was admitted to the surgery ward with left breast mass since 2-3 months ago. In past medical history, the patient had left breast surgery due to fibrocystic change seven years ago. Grossly her specimen consisted in a piece of gray soft tissue measuring $10 * 8 * 4.5 \mathrm{~cm}$ with lobulated appearance and small cystic areas. In permanent diagnosis, the pathologist reported low-grade malignant (borderline) PT. Microscopically the tumor was composed of benign glandular elements and hypercellular spindle-shaped stroma. Mitotic index was 3/10 high power field (HPF). The border was well-circumscribed with satellite lesion. In conclusion, the diagnosis of borderline phyllodes tumor cannot be made only on age, the size of tumor, imaging or clinical features. Microscopic evaluation with evaluation of stromal cellularity, atypia, mitotic counts and border of the tumor is necessary for definite diagnosis and categorizing of this tumor.
\end{abstract}

Keywords: phyllodes tumor, borderline, case report

Cite This Article: Mazaher Ramezani, and Masoud Sadeghi, "Low Grade Malignant (Borderline) Phyllodes Tumor of the Breast: Case Report and Review of Literature." Journal of Cancer Research and Treatment, vol. 5, no. 3 (2017): 89-91. doi: 10.12691/jcrt-5-3-3.

\section{Introduction}

Phyllodes tumors (PTs) have an incidence of 1 per 100,000 women and account for only $0.5 \%$ of all breast malignancies [1]. PT of the breast is a rare disease usually presents as a large lump. In few cases, it is bilateral or multifocal [2,3]. These neoplasms generally present as unilateral painless, well-circumscribed, mobile breast masses in women 35 to 55 years old [4]. PTs are classified according to their biological behavior to benign, malignant and borderline [5]. Most PTs are benign (63-78\%), with borderline PTs diagnosed in only $11-30 \%$ cases [6]. They are more prevalent in the Latin American, White and Asian populations [7]. The difficulty in distinguishing between PTs and benign fibroadenoma may lead to misdiagnosis. In fact, there are no characteristic features that clinically distinguish PTs from other breast cancers [8]. The aim of this study was to report low grade malignant (borderline) PT of the breast in Kermanshah, Iran.

\section{Case Report}

A 55-year-old lady was admitted to the surgery ward on April 26 $6^{\text {th }}$, 2017 with left breast mass since 2-3 months ago. The mass was non-tender without discharge or nipple retraction, but with an increase in size according to the patient's report. In past medical history, the patient was menopause since eleven years ago and had left breast surgery due to fibrocystic change seven years ago. No significant drug or relevant family history was noted. On physical examination vital signs were stable. Large non-tender mass measuring $8 * 5 \mathrm{~cm}$ in pre areolar and upper part of the nipple and breast was present. The consistency was firm. Overlying skin showed mild telangiectasia. Axillary mass was not found.
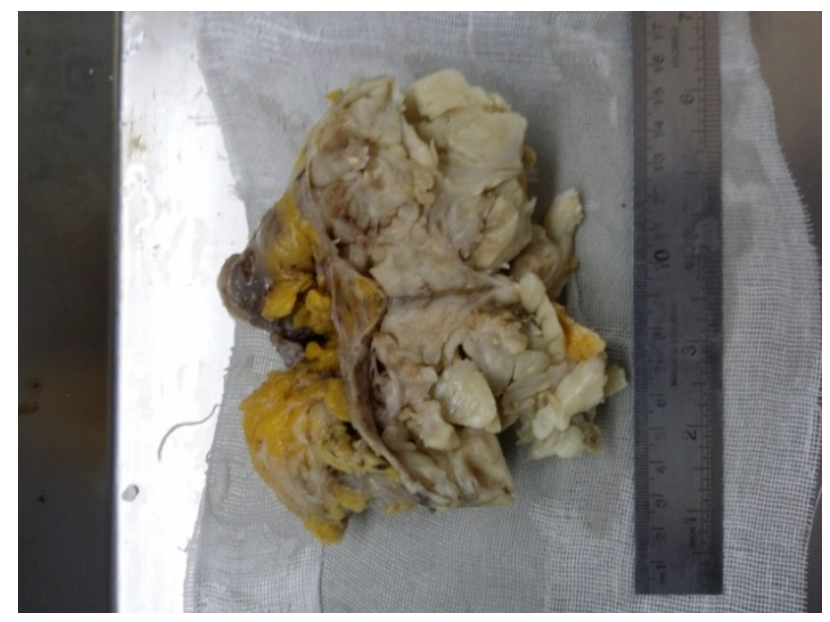

Figure 1. Gross specimen

Laboratory data revealed that CBC (complete blood count), PT, PTT, Blood Sugar, Urea, Cr, AST, ALT, Alkaline phosphatase, Albumin, Bilirubin, $\mathrm{Na}, \mathrm{K}$ and $\mathrm{Ca}$ 
were normal. The patient underwent surgery on April $27^{\text {th }}$, 2017. The specimen was sent to the pathology department for frozen section and then permanent diagnosis. Grossly the specimen was consisted in a piece of gray soft tissue measuring $10 * 8 * 4.5 \mathrm{~cm}$ with lobulated appearance and small cystic areas (Figure 1). Frozen section diagnosis was PT. In permanent diagnosis, the pathologist reported lowgrade malignant (borderline) PT (Figure 2 and Figure 3). Microscopically the tumor was composed of benign glandular elements and hypercellular spindle-shaped stroma. Mitotic index was 3/10 high power field (HPF). The border was well-circumscribed with satellite lesion. Tumor greatest diameter was $10 \mathrm{~cm}$. The patient was in good condition on May $7^{\text {th }}, 2017$.

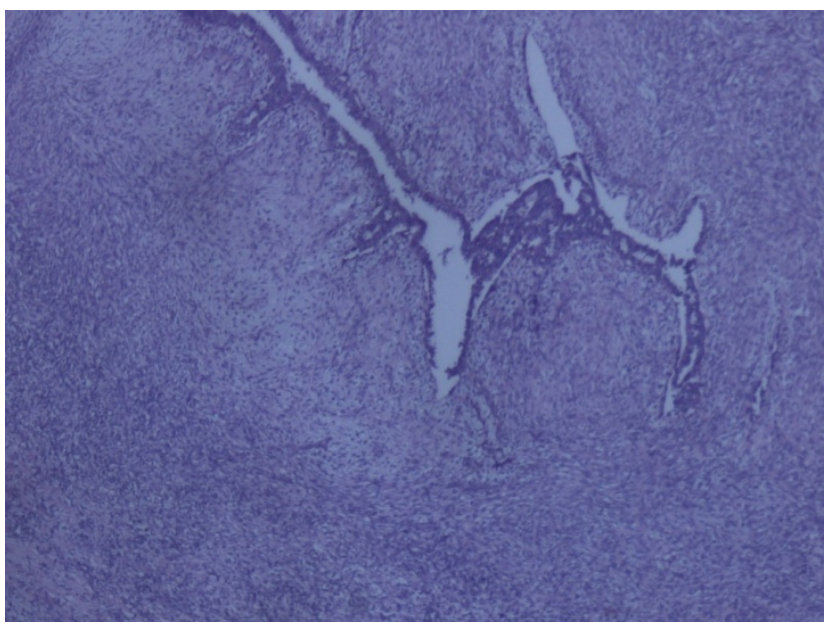

Figure 2. Phyllodes tumor, Borderline, Hematoxylin \& Eosin Stain (x 40)

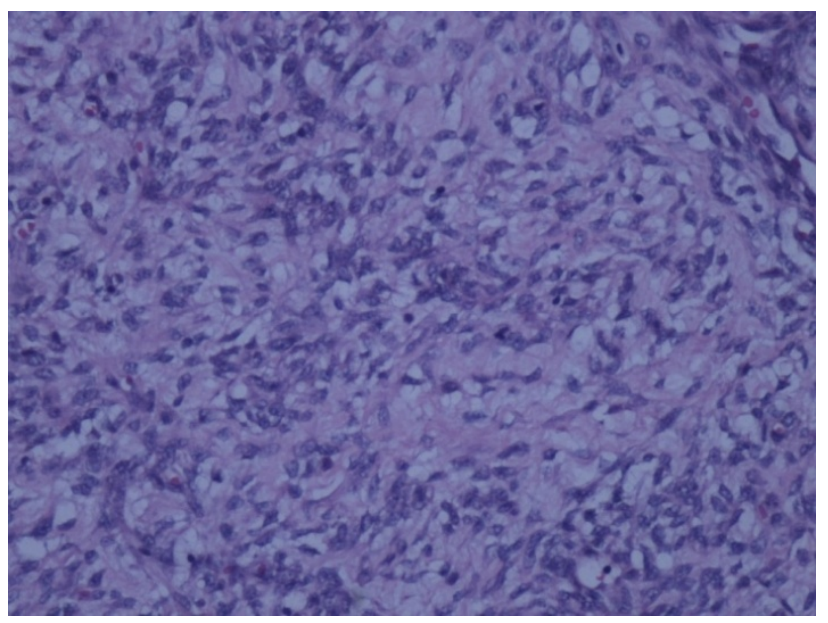

Figure 3. The same tumor, Hematoxylin \& Eosin Stain (x 200)

\section{Discussion}

This study reported a 55-year-old lady with low-grade malignant (borderline) PT of the left breast without axillary node involvement with a tumor size of $10 \mathrm{~cm}$ and mitotic index of $3 / 10 \mathrm{HPF}$ that the tumor was well circumscribed with cystic areas. This is the second case reported in Kermanshah, Iran. [1] Malignant PT represents less than $1 \%$ of all breast malignancies and commonly has an indolent clinical course with a propensity for local recurrence [9]. Abusalem et al. [10] reported that in their study, the mean age of patients with borderline PT was 42 years and higher than benign (37 years) and malignant (41 years) Ts. Also, PTs were more frequently situated in left breast than in the right side (58\% vs. $42 \%$ respectively).

Axillary node involvement is rare. Another characteristic feature of these tumors is a high rate of local recurrences (5-20\%) [11]. The median size of PTs is around $4 \mathrm{~cm}$. Twenty percent of the tumors grow larger than $10 \mathrm{~cm}$ (giant PT). These tumors can reach sizes up to $40 \mathrm{~cm}$ in diameter [12].

Surgery is the primary option for the treatment of malignant PT of the breast [13] that in one research for borderline and malignant PTs of the breast, a total mastectomy was superior to breast-conserving surgery in order to guarantee adequate safe margins [14].

Murthy et al. [15] reported a 25-year-old lactating mother presenting with a lump in the left breast that gross photograph of her specimen demonstrating a grayishwhite well-circumscribed mass with solid and cystic areas. Microscopic findings include fibroepithelial proliferation in a classic leaf-like pattern. Borderline tumors have moderately cellular stroma, 5-9 mitotic figures per $10 \mathrm{HPF}$ with mild-to-moderate atypia, whereas malignant tumors, exhibit marked cellularity, atypia, brisk mitotic activity (>10/10 HPFs), infiltrative borders, and stromal overgrowth $[16,17]$. Another study showed that borderline tumors have 4-10 mitotic figures per $10 \mathrm{HPF}$ [18], but Kim et al. [19] reported that borderline tumors had 2-5 mitoses per $10 \mathrm{HPF}$. Fou et al. suggested a $75 \%$ mortality in metastatic phyllodes with mitotic index $>10$ per HPF [20]. Mammography showed well-circumscribed oval or lobulated mass with rounded borders [21]. Jorge Blanco et al. [22] reviewed the clinical, radiologic, and pathologic findings of 12 cases of PTs diagnosed in their hospital in the past 6 years, 6 of which were malignant. At ultrasound examination, all tumors were well-circumscribed and eight patients showed internal cystic areas. There is a controversy for considering a breast tumor with hypercellular stroma as borderline phyllodes tumor. In our case, the presence of satellite lesion and more than 2 mitoses per $10 \mathrm{HPF}$ was considered as adequate criteria to put the tumor in borderline category.

\section{Conclusions}

Diagnosis of borderline phyllodes tumor cannot be made only on age, the tumor size, imaging or clinical features. Microscopic evaluation with an assessment of stromal cellularity, atypia, mitotic counts and border of the tumor is necessary for definite diagnosis and categorizing of this tumor.

\section{References}

[1] Payandeh M, Usefi H, Sadeghi E, Sadeghi M. Malignant Phyllodes Tumor in Patient with Breast Cancer: A Case Report. American Journal of Cancer Prevention. 2015; 3(3): 62-4.

[2] Lenhard MS, Kahlert S, Himsl I, Ditsch N, Untch M, Bauerfeind I. Phyllodes tumour of the breast: clinical follow-up of 33 cases of this rare disease. Eur J Obstet Gynecol Reprod Biol. 2008; 138(2): 217-21.

[3] Grabowski J, Salzsrein SL, Sadler GR, Blair SL. Malignant phyllodes tumors: a review of 752 cases. Am Surg. 2007; 73(10): 967-9. 
[4] Ben Hassouna J, Damak T, Gamoudi A, Chargui R, Khomsi F, Mahjoub S, et al. Phyllodes tumors of the breast: A case series of 106 patients. Am J Surg. 2006; 192: 141-7.

[5] Mrad K, Driss M, Maalej M, Romdhane KB. Bilateral cystosarcoma phyllodes of the breast: A case report of malignant form with contralateral benign form. Ann Diagn Pathol. 2000; 4(6): 370-2.

[6] Lee JY. Giant phyllodes tumor of the breast with diffuse myxoid changes in an adolescent girl: a case report. J Surg Case Rep. 2017; 2017(2): rjx019.

[7] Islam S, Shah J, Harnarayan P, Naraynsingh V. The largest and neglected giant phyllodes tumor of the breast-A case report and literature review. Int J Surg Case Rep. 2016; 26: 96=100.

[8] Testori A, Meroni S, Errico V, Travaglini R, Voulaz E, Alloisio M. Huge malignant phyllodes breast tumor: a real entity in a new era of early breast cancer. World J Surg Oncol. 2015; 13: 81.

[9] Al-Zoubaidi M, Qiu S, Bonnen M, Joyner M, Roehl K, Silva C, Chao C. Malignant Phyllodes Tumor of the Breast: A Case Report. Can J. 2011;3:45-8.

[10] Abusalem OT, Al-Masri A. Phyllodes Tumors of the Breast. Mater Sociomed. 2011;23(4):200-5.

[11] Mylvaganam S, Toro C, Frank L, Vesty S, Thrush S. Phyllodes tumors of the breast: best practice for follow-up. Updat Surg. 2015;67(1):91-5.

[12] Mishra SP, Tiwary SK, Mishra M, Khanna AK. Phyllodes tumor of breast: a review article. ISRN Surg. 2013; 361469.

[13] Khan SA, Badve S. Phyllodes tumors of the breast. Curr Treat Options Oncol. 2001; 2(2): 139-47.
[14] Belkacémi Y, Bousquet G, Marsiglia H, Ray-Coquard I, Magné N, Malard Y, et al. Phyllodes tumor of the breast. Int J Radiat Oncol Biol Phys. 2008; 70(2):492-500.

[15] Murthy SS, Raju KV, Nair HG. Phyllodes Tumor in a Lactating Breast. Clin Med Insights Pathol. 2016; 9: 13-7.

[16] Lakhani SR, Ellis IO, Schnitt SJ, Tan PH, Van de Vijver MJ. WHO Classification of Tumours of the Breast. 4th ed. Lyon: IARC Press. 2012. pp. 143-7.

[17] Spitaleri G, Toesca A, Botteri E, Bottiglieri L, Rotmensz N, Boselli S, et al. Breast phyllodes tumor: a review of literature and a single center retrospective series analysis. Crit Rev Oncol Hematol. 2013; 88(2):427-36.

[18] Mallick S, Joshi NP, Roy S, Gandhi AK, Pandit S, Sharma D, et al. Malignant and borderline phyllodes tumor of breast treated with a multi-modality approach in a tertiary cancer care centre in North India. South Asian J Cancer. 2016; 5(1): 1-3.

[19] Kim HJ, Kim TS, Kang HJ, Cho HJ, Park IA, Noh DY, et al. Clinical Analysis of Phyllodes Tumor of the Breast. Journal of the Korean Surgical Society. 2000;58(3): 352-60.

[20] Fou A, Schnabel FR, Hamele-Bena D, Wei XJ, Cheng B, El Tamer M, et al. Long-term outcomes of malignant phyllodes tumors patients: An institutional experience. Am J Surg. 2006; 192(4): 492-5.

[21] Feder JM, de Paredes ES, Hogge JP, Wilken JJ. Unusual breast lesions: radiologic-pathologic correlation. Radiographics. 1999;19 Spec No:S11-S26; quiz S260.

[22] Jorge Blanco A, Vargas Serrano B, Rodríguez Romero R, Martínez Cendejas E. Phyllodes tumors of the breast. Eur Radiol. 1999; 9(2): 356-60. 